\title{
Probiotic fermentation augments the skin anti-photoaging properties of Agastache rugosa through up-regulating antioxidant components in UV-B-irradiated $\mathrm{HaCaT}$ keratinocytes
}

Daehyun Shin ${ }^{1,2+}$, Yoonjin Lee ${ }^{1 \dagger}$, Yu-Hua Huang ${ }^{3}$, Hye-Won Lim³ ${ }^{3}$ Kyounghee Jang ${ }^{1}$, Dae-Duk Kim²* and Chang-Jin Lim,

\begin{abstract}
Background: Agastache rugosa (Fisch. \& C.A.Mey.) Kuntze (Korean mint) is used to treat diverse types of human disorders in traditional medicine. In recent years, its non-fermented leaf extract (ARE) has been shown to possess protective properties against ultraviolet-B (UV-B) radiation-induced photooxidative stress. The present work aimed to examine whether probiotic bacterial fermentation would potentiate the skin anti-photoaging activity of ARE or not, by comparing the protective properties of ARE and corresponding fermented extract (ARE-F) against UV-B radiation-induced photooxidative stress in $\mathrm{HaCaT}$ keratinocytes.

Methods: ARE-F was produced from ARE by the fermentation with Lactobacillus rhamnosus HK-9, a type of Gram-positive probiotic bacterial strain. Anti-photoaging activities were evaluated by analyzing reactive oxygen species (ROS), promatrix metalloproteinases (proMMPs), total glutathione (GSH) and total superoxide dismutase (SOD) in UV-B-irradiated HaCaT keratinocytes. Antiradical activity was determined using 2,2-azino-bis(3-ethylbenzothiazoline-6sulfonic acid) (ABTS) radical scavenging assay.

Results: ARE-F contained higher attenuating activity on the UV-B-induced ROS generation than ARE. Similarly, ARE- $F$ was able to diminish the UV-B-induced proMMP-9 and -2 more effectively than ARE. ARE-F displayed higher tendencies to augment the UV-B-reduced total GSH content and SOD activity than ARE. However, there were no significant difference between ARE and ARE-F in ABTS radical scavenging activities.
\end{abstract}

Conclusions: The findings suggest that the UV-B radiation-protective activity of ARE is enhanced by probiotic bacterial fermentation, which might improve the therapeutic and cosmetic values of A. rugosa leaves.

Keywords: Agastache rugosa, Anti-photoaging, Glutathione, HaCaT, Matrix metalloproteinase (MMP), Probiotic fermentation, Reactive oxygen species (ROS), Superoxide dismutase

\footnotetext{
* Correspondence: ddkim@snu.ac.kr; cjlim@kangwon.ac.kr

${ }^{\dagger}$ Daehyun Shin and Yoonjin Lee contributed equally to this work.

${ }^{2}$ College of Pharmacy and Research Institute of Pharmaceutical Sciences,

Seoul National University, Seoul 08826, Republic of Korea

${ }^{3} \mathrm{R}$ \& D Center, Shebah Biotech Inc., G-Tech Village, Chuncheon 24398,

Republic of Korea

Full list of author information is available at the end of the article
}

(c) The Author(s). 2018 Open Access This article is distributed under the terms of the Creative Commons Attribution 4.0 International License (http://creativecommons.org/licenses/by/4.0/), which permits unrestricted use, distribution, and reproduction in any medium, provided you give appropriate credit to the original author(s) and the source, provide a link to the Creative Commons license, and indicate if changes were made. The Creative Commons Public Domain Dedication waiver (http://creativecommons.org/publicdomain/zero/1.0/) applies to the data made available in this article, unless otherwise stated. 


\section{Background}

Skin aging, concisely defined as an impairment of skin integrity, is classified into the two main types: intrinsic or chronologic aging and extrinsic aging or photoaging. Intrinsic aging comes from the common process of senescence affecting all body organs, whereas photoaging occurs as a consequence of chronic exposure to environmental factors, especially solar ultraviolet (UV) radiation, and is characterized by skin fragility, wrinkle, roughness, sagging, dryness, laxity and hyper-pigmentation $[1,2]$.

The three types of UV radiation - UV-A, UV-B and UV-C - have different wavelength ranges. Although UV$C$ radiation $(100-280 \mathrm{~nm})$ is extremely damaging to the skin, it is almost completely absorbed by the ozone layer and thus has no adverse effects. Despite being more penetrating deeper in the skin, less energetic UV-A radiation (315-400 $\mathrm{nm})$ has been considered to be less harmful. Recent studies implicate that UV-A radiation can cause skin cancer indirectly via generating highly reactive chemical intermediates, such as free radicals and ROS, which in turn can damage DNA [3]. UV-B radiation $(280-315 \mathrm{~nm})$ constitutes only $5 \%$ of the total solar UV energy and is considered the most damaging and genotoxic, which is chiefly responsible for various sun-induced skin disorders, including sunburn, photoaging, oxidative damage, erythema, acute inflammation, immunosuppression, and nonmelanoma and melanoma skin cancers [3, 4]. UV-B radiation can cause DNA damage as a consequence of its direct action on DNA molecule resulting in the formation of cyclobutane-pyrimidine dimers, 6-4 photoproducts, Dewar isomers and 8hydroxy-2'-deoxyguanosine, and indirectly increase ROS levels, which, in case of overwhelming the cellular antioxidant defense capacity, leads to oxidative stress and subsequently oxidative photolesions of macromolecules, such as DNA, proteins and lipids, in the skin $[5,6]$. ROS participate in diverse UV-B-induced pathophysiological processes by activating mitogen-activated protein kinase (MAPK) and nuclear factor- $\mathrm{kB}$ (NF-kB) [7].

Although MMPs play a role in normal tissue development, remodeling and repair, they are closely linked to tissue destruction in a number of pathological conditions, including inflammation, UV-induced skin damage and tumor invasion $[8,9]$. MMP-2 and -9 , belonging to the gelatinase group of MMPs, degrade the extracellar matrix (ECM) via degrading type IV collagen, the most abundant components of the basement membrane which is important for maintaining tissue organization, providing structural support for cells and influencing cell signaling and polarity, and influence skin wrinkle formation and skin thickness [10]. The exposure of human skin to UV radiation up-regulates the synthesis of various MMPs, including MMP-1, $-2,-3,-7,-8,-9$ and -12 , which are implicated in photoaging [10]. MMP-2 and -9 are expressed at elevated levels in a variety of cell types under oxidative stress $[11,12]$.

A. rugosa is a perennial herb belonging to the mint family (Lamiaceae) cultivated in East Asian Countries, including Korea, and has been used to treat colds, anorexia, cholera, vomiting, miasma and other kinds of disorders [13]. A variety of essential oils, such as methyleugenol, estragole and eugenol, and diverse types of flavonoids, such as tilianin, acacetin, linarin, agastachoside and rosmarinic acid, have been identified from $A$. rugosa [14]. Two diterpenoid compounds, agastanol and agastaquinone, and two lignin compounds, agastinol and agastenol, were also identified from $A$. rugosa $[15,16]$. A range of biological and pharmacological activities of $A$. rugosa, including antimicrobial, antifungal, insecticidal, antiviral, antihypertensive, anti-inflammatory, anticancer, antioxidative, antiatherogenic and vasorelaxant activities, have been documented [17-20].

Probiotic bacterial fermentation, emerging as one of crucial processing tools in cosmetic technologies, is used to diminish toxicities of cosmetic resources, enhance absorption into the skin by altering their molecular structures, and improve their desirable pharmacological activities [21].

Throughout the previous work, ARE was reported to have an attenuating potential against the UV-B-induced photoaging of human skin [22]. In the present work, it is demonstrated that the skin anti-photoaging activity of ARE can be potentiated by probiotic bacterial fermentation. This finding might possibly broaden the usefulness of $A$. rugosa in therapeutic as well as cosmetic applications.

\section{Methods}

\section{Chemicals}

Bradford reagent, bovine serum albumin, ascorbic acid (AA), 2,2-azino-bis(3-ethylbenzothiazoline-6-sulfonic acid) (ABTS), ammonium persulfate, $2^{\prime}, 7^{\prime}$-dichlorodihydrofluorescein diacetate (DCFH-DA), 5,5'-dithiobis (2-nitrobenzoic acid) (DTNB), glutathione reductase (GR), catalase, xanthine, xanthine oxidase and NADPH were from SigmaAldrich Chemical Co. (St Louis, MO, USA). Cell lysis buffer [25 mM Tris-phosphate (pH 7.8), $2 \mathrm{mM} \mathrm{1,2-diami-}$ nocyclohexane- $N, N, N v, N v$-tetraacetic acid, $2 \mathrm{mM}$ dithiothreitol, 10\% glycerol, 1\% Triton X-100] was from Promega Korea (Seoul, Korea).

\section{Plant material}

Dried $A$. rugosa leaves, obtained from a local market in Chuncheon, Korea, were authenticated by Prof. Ki-Oug Yoo (Department of Biological Sciences, College of Natural Sciences, Kangwon National University, Chuncheon, Korea). A voucher specimen (No. KWNU90446) was deposited at the herbarium in the same department. 


\section{Preparation of ARE and ARE-F}

As previously described [22], ARE was prepared as follows. Dried A. rugosa leaves, ground under liquid nitrogen, were extracted under reflux by placing in a water bath at $90{ }^{\circ} \mathrm{C}$ for $4 \mathrm{~h}$. After being filtered through a filter paper, the hot water extract was evaporated to dryness in a freeze dryer, and the extract powder was designated as ARE. The yield was approximately $10.4 \%$.

ARE, resuspended in distilled water, was incubated at $30{ }^{\circ} \mathrm{C}$ for 5 days with L. rhamnosus HK-9 (KACC 11254P, Korea), centrifuged at $5000 \mathrm{~g}$ for $20 \mathrm{~min}$ to discard bacterial cells, and concentrated using a freeze dryer to generate fermented extract powder, designated as ARE-F. Prior to the experiments, both ARE and ARE$\mathrm{F}$ were dissolved in dimethyl sulfoxide, and control cells were treated with vehicle only ( $0.1 \%$ dimethyl sulfoxide). The vehicle itself had no damaging effect on the viabilities of $\mathrm{HaCaT}$ cells.

\section{Cell culture}

A human immortalized $\mathrm{HaCaT}$ keratinocyte cell line (ATCC No. CRL-2309) was obtained from American Type Culture Collection (Manassas, VA, USA) and grown in Dulbecco's Modified Eagle's Medium (DMEM) with $10 \%$ heat-inactivated fetal bovine serum (FBS), 100 units $/ \mathrm{mL}$ penicillin and $100 \mu \mathrm{g} / \mathrm{mL}$ streptomycin in a humidified atmosphere with $5 \% \mathrm{CO}_{2}$ at $37^{\circ} \mathrm{C}$.

\section{UV-B irradiation}

As a UV-B source, an ultraviolet lamp (peak, $312 \mathrm{~nm}$; model VL-6 M, Vilber Lourmat, Marine, France) was used with a radiometer (model VLX-3 W) equipped with a sensor (bandwidth, 280 to $320 \mathrm{~nm}$; model CX-312). In the present work, $\mathrm{HaCaT}$ keratinocyte culture at $25{ }^{\circ} \mathrm{C}$ were irradiated with solar simulated UV-B radiation at $70 \mathrm{~mJ} / \mathrm{cm}^{2}$, an intensity chosen to induce a photooxidative stress through a preliminary experiment.

\section{Preparation of cellular lysate}

At $18 \mathrm{~h}$ after irradiation, adherent cells, washed twice with PBS and stored on ice for $5 \mathrm{~min}$, were collected using a cell scraper, centrifuged at $5000 \mathrm{~g}$ for $10 \mathrm{~min}$, resuspended in cell lysis buffer and stored for $30 \mathrm{~min}$ on ice. Cellular lysate was taken out after centrifugation at $5000 \mathrm{~g}$ for $15 \mathrm{~min}$.

Protein content in cellular lysates was quantitated with the Bradford protein assay [23] using bovine serum albumin as a reference standard to construct a calibration curve.

\section{Quantitation of intracellular ROS}

As previously described [24], a redox-sensitive fluorescent probe DCFH-DA, which generates the fluorescent $2^{\prime}, 7^{\prime}$ dichlorofluorescein (DCF; $\lambda_{\text {excitation }}=485 \mathrm{~nm}, \lambda_{\text {emission }}=$
$530 \mathrm{~nm}$ ) upon enzymatic reduction and subsequent oxidation by ROS, was utilized to detect intracellular ROS. After $\mathrm{HaCaT}$ keratinocytes were treated with ARE and ARE-F and/or $20 \mu \mathrm{M}$ DCFH-DA for $30 \mathrm{~min}$ at $37{ }^{\circ} \mathrm{C}$, they were washed twice with $1 \mathrm{~mL}$ FBS-free DMEM. The cells, resuspended in $1 \mathrm{~mL}$ FBS-free DMEM, were irradiated with UV-B radiation. Immediately after the irradiation, the intracellular ROS levels were determined by monitoring the DCF fluorescence using a multi-mode microplate reader $\left(\right.$ Synergy ${ }^{\mathrm{Tm}} \mathrm{Mx}$, BioTek Instruments, Winooki, VT, USA).

\section{Western blotting analysis}

Western blotting analyses were conducted to detect proMMP-2 and -9 in cellular lysate using anti-MMP-2 (ALX-210-753, Enzo Life Sciences, Farmingdale, NY, USA) and anti-MMP-9 (3852S, Cell Signaling Technology, Danvers, MA, USA) antibodies. Glyceraldehyde 3phosphate dehydrogenase (GAPDH), used as an internal loading standard, was detected using anti-GAPDH antibody (LF-PA0212, AbFrontier, Seoul, Korea). Cellular lysates were separated on $10 \%(w / v)$ SDS-PAGE and electrotransferred to PVDF membrane. After the blotted membrane was probed with primary antibodies overnight at $4{ }^{\circ} \mathrm{C}$, it was incubated with secondary antibody (goat anti-rabbit IgG-pAb-HRP-conjugate; ADI-SAB300, Enzo Life Sciences, Farmingdale, NY, USA) for $1 \mathrm{~h}$ at room temperature, and developed using an enhanced West-save up ${ }^{\mathrm{Tm}}$ (AbFrontier, Seoul, Korea).

\section{Determination of total GSH}

Total GSH content in cellular lysates was determined using an enzymatic recycling assay based on GR [25]. The reaction mixture $(200 \mu \mathrm{L})$, which contained $175 \mathrm{mM} \mathrm{KH}_{2} \mathrm{PO}_{4}, 6.3 \mathrm{mM}$ EDTA, $0.21 \mathrm{mM}$ NADPH, 0. $6 \mathrm{mM}$ DTNB, 0.5 units/mL GR and cellular lysate, was incubated at $25{ }^{\circ} \mathrm{C}$. A change in absorbance at $412 \mathrm{~nm}$ was monitored using a microplate reader. Total GSH contents were calculated from a calibration curve constructed with various GSH concentrations, and normalized to the total protein content of cellular lysates, which gave rise to total GSH content in $\mu \mathrm{g} / \mathrm{mg}$ protein.

\section{Determination of SOD activity}

Total SOD activity in cellular lysates was determined as the reduction of cytochrome $\mathrm{c}$ with xanthine/xanthine oxidase system [26]. The reaction mixture $(200 \mu \mathrm{L})$, contained $50 \mathrm{mM}$ phosphate buffer ( $\mathrm{pH}$ 7.4), 0.01 units $/ \mathrm{mL}$ xanthine oxidase, $0.1 \mathrm{mM}$ EDTA, $1 \mu \mathrm{M}$ catalase, $0.05 \mathrm{mM}$ xanthine, $20 \mu \mathrm{M}$ cytochrome $\mathrm{c}$ and cellular lysate. A change in absorbance at $550 \mathrm{~nm}$ was monitored using a microplate reader. The SOD activity was normalized by determining the protein content of cellular lysates, and represented as $\Delta \mathrm{A}_{550} / \mathrm{min} / \mathrm{mg}$ protein. 


\section{Quantitation of antiradical activity}

Antiradical activities of ARE and ARE-F were detected using ABTS radical scavenging assay [27] with a slight modification. ABTS radical cations $\left(\mathrm{ABTS}^{+}\right)$, produced by reacting ABTS stock solution $(0.07 \mathrm{mM})$ with 0 . $12 \mathrm{mM}$ ammonium persulfate, were kept to stand in the dark at room temperature for $16 \mathrm{~h}$ before use. The varying concentrations of ARE and ARE-F (each $10 \mu \mathrm{L}$ ) were mixed with $290 \mu \mathrm{L}$ of $\mathrm{ABTS}^{+}$solution and the final volume was made up to $1 \mathrm{~mL}$ with ethanol. The reaction mixture was incubated for $15 \mathrm{~min}$ in the dark at room temperature. AA was used as a positive control. The absorbance was measured at $745 \mathrm{~nm}$ and the percent inhibition by ARE and ARE-F was calculated using the formula, Inhibition $(\%)=[($ Control - Test $) /$ Control] $\times 100$. The AA concentration eliciting $50 \%$ scavenging of $\mathrm{ABTS}^{+}$radicals $\left(\mathrm{SC}_{50}\right)$ was calculated.

\section{Statistical analysis}

The data were expressed as mean \pm SD. Differences between experimental groups were analyzed using one-way ANOVA followed by post hoc Tukey HSD test for multiple comparisons. A $P$ value $<0.05$ was considered statistically significant.

\section{Results}

\section{Reactive oxygen species (ROS)}

ROS are generated by exogenous (environmental) sources, such as UV irradiation and heat exposure, in addition to their production as natural byproducts of the normal cellular metabolism of oxygen. Oxidative stress, which refers to the excessively elevated intracellular levels of ROS and participate in a myriad of pathologies, arises from an imbalance between the production of ROS and the cellular capability to scavenge the reactive intermediates and to repair the resulting damage. ROS levels, one of principal markers of oxidative stress, are considered to reflect the degree of oxidative stress.

When $\mathrm{HaCaT}$ keratinocytes were irradiated with $70 \mathrm{~mJ} / \mathrm{cm}^{2}$ UV-B radiation, the intracellular ROS levels went up to approximately 15.3 -fold (Fig. 1). This result could prove that UV-B irradiation, at the intensity chosen in this work, can impose a state of oxidative stress on $\mathrm{HaCaT}$ keratinocytes. However, the radiation intensity used couldn't interfere with the viabilities of $\mathrm{HaCaT}$ keratinocytes, which was detected using an MTT assay (data not shown). When $\mathrm{HaCaT}$ keratinocytes were subjected to varying concentrations $(5,20$ and $80 \mu \mathrm{g} / \mathrm{mL})$ of ARE prior to the irradiation, ARE attenuated the UV-Binduced ROS levels to. 57.4, 55.7 and $32.8 \%$, respectively (Fig. 1a). In the same pretreatment, ARE-F, at the concentrations of 5,20 or $80 \mu \mathrm{g} / \mathrm{mL}$, could attenuate the UV-Binduced ROS levels to $60.7,36.1$ and $13.1 \%$, respectively (Fig. 1b). ARE exhibited an $\mathrm{IC}_{50}$ value of $27.0 \mu \mathrm{g} / \mathrm{mL}$,

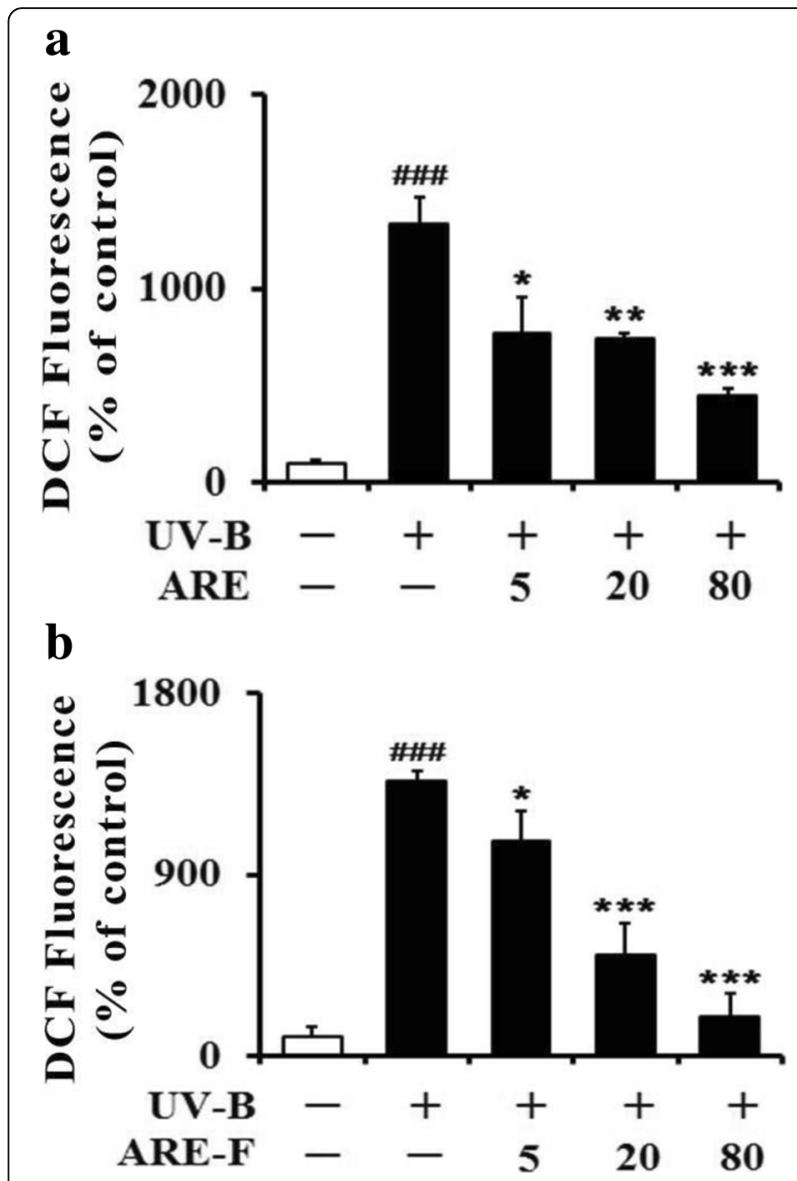

Fig. 1 Suppressive effects of $A R E,(\mathbf{a})$ and $A R E-F(\mathbf{b})$ on the ROS levels in $\mathrm{HaCaT}$ keratinocytes under UV-B irradiation. HaCaT cells were subjected to the varying concentrations $(0,5,20$ and $80 \mu \mathrm{g} / \mathrm{mL})$ of ARE (a) and ARE-F (b) for $1 \mathrm{~h}$ before the irradiation. The ROS levels were determined using DCFH-DA in a microplate fluorometer, and represented as DCF fluorescence, expressed as a percentage (\%) of the corresponding non-irradiated control. ${ }^{\# \#} P<0.001$ versus the non-irradiated control. ${ }^{*} P<0.05$; ${ }^{* *} P<0.01 ;{ }^{* *} P<0.001$ versus the non-treated control (UV-B irradiation alone)

whereas that of ARE-F was determined to be $17.4 \mu \mathrm{g} / \mathrm{mL}$. Collectively, ARE-F has an enhanced attenuating activity on the UV-B-induced ROS levels than ARE, implying that the intracellular antioxidative activity of ARE can be augmented by probiotic bacterial fermentation.

\section{Promatrix metalloprtoenase-9 (proMMP-9) and - 2 (proMMP-2)}

The skin photoaging activity of UV-B radiation is mediated by the enhancement of diverse MMPs by UV-Binduced ROS. MMP-1, -9 and -2 , known to be directly involved in the impairment of ECM components, were shown to be up-regulated by UV-B radiation [10]. Even the precursor forms (proMMP-9 and -2) of MMP-9 and -2 were previously identified to be enhanced in $\mathrm{HaCaT}$ 
keratinocytes by UV-B irradiation [28]. As shown in Fig. 2, the UV-B irradiation alone could give rise to approximately 2.0-fold elevation in the proMMP-9 protein level over that in the non-irradiated control cells. $\mathrm{HaCaT}$ keratinocytes were subjected to varying concentrations $(0,5$, 20 and $80 \mu \mathrm{g} / \mathrm{mL}$ ) of ARE prior to UV-B irradiation. ARE at the concentrations of 5,20 and $80 \mu \mathrm{g} / \mathrm{mL}$ made the UV-B-induced proMMP-9 elevation reduce to 96.1, 72.5 and $54.9 \%$ of that from the UV-B irradiation alone, respectively (Fig. 2a). As shown in Fig. 2b, the attenuating

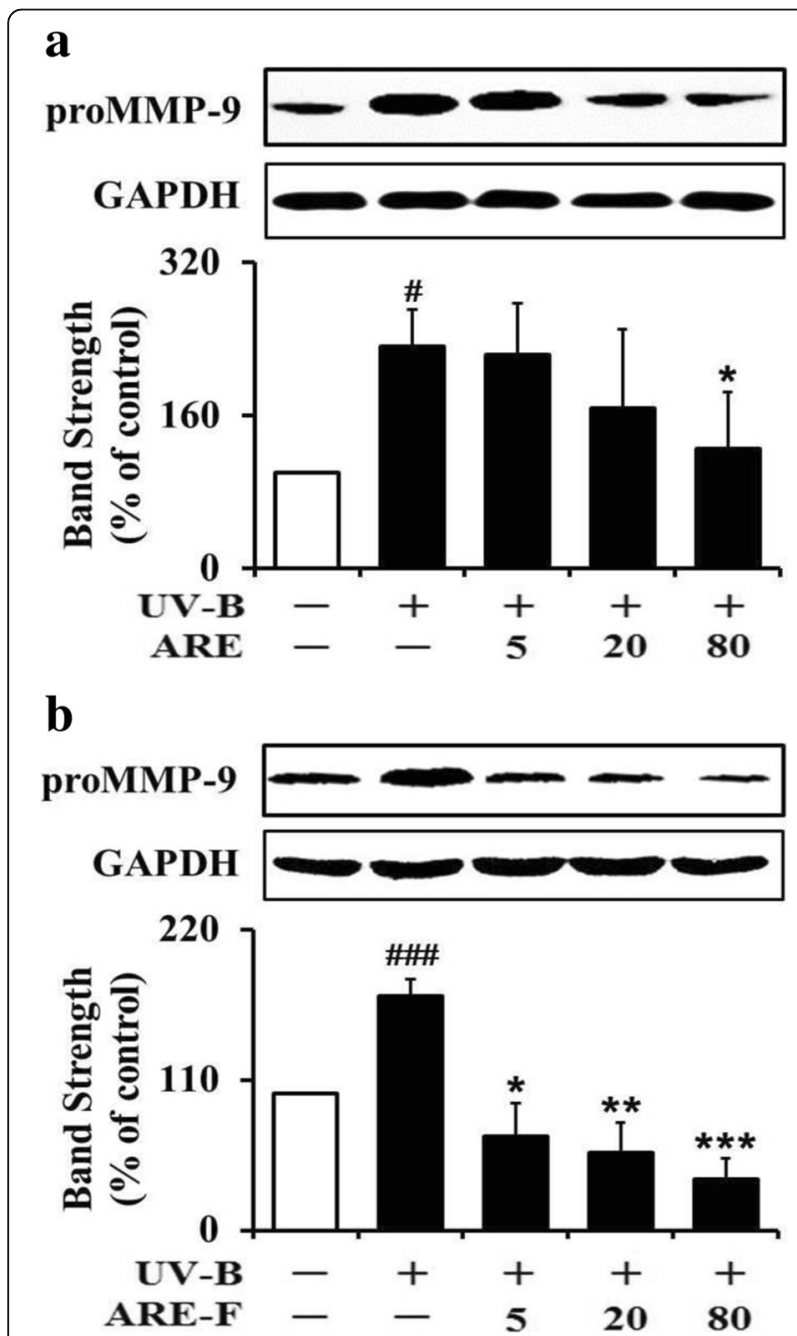

Fig. 2 Suppressive effects of ARE (a) and ARE-F (b) on the proMMP-9 elevation in $\mathrm{HaCaT}$ keratinocytes under UV-B irradiation. $\mathrm{HaCaT}$ cells were subjected to the varying concentrations $(0,2,20$ and $80 \mu \mathrm{g} / \mathrm{mL})$ of ARE (a) and ARE-F (b) for $1 \mathrm{~h}$ before the irradiation. The proMMP-9 proteins in cellular lysates, detected using western blotting analysis, were expressed as a percentage (\%) of the corresponding nonirradiated control. In the lower panels of both $\mathbf{a}$ and $\mathbf{b}$, the band strength was determined with densitometry using the ImageJ software which can be downloaded from the $\mathrm{NIH}$ website. ${ }^{\sharp} P<0.05$;

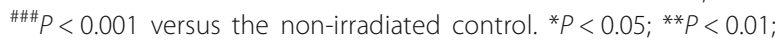
${ }^{*}{ }^{*} P<0.001$ versus the non-treated control (UV-B irradiation alone) activity of ARE-F was also examined in a similar way. ARE-F at the concentrations of 5,20 and $80 \mu \mathrm{g} / \mathrm{mL}$ was able to attenuate the UV-B-induced proMMP-9 elevation to $39.6,32.1$ and $20.8 \%$, respectively (Fig. $2 \mathrm{~b}$ ). The $\mathrm{IC}_{50}$ values of ARE and ARE-F in the attenuating activities on proMMP-9 were 91.8 and $11.2 \mu \mathrm{g} / \mathrm{mL}$, respectively. In brief, ARE-F has higher attenuating activity on the UV-Binduced proMMP-9 elevation than ARE.

As shown in Fig. 3, the attenuating activities of both ARE and ARE-F on the UV-B-induced proMMP-2 levels were also measured and compared. The UV-B irradiation alone induced the proMMP-2 protein levels to about 1.7fold over the non-irradiated control value (Fig. 3). ARE at

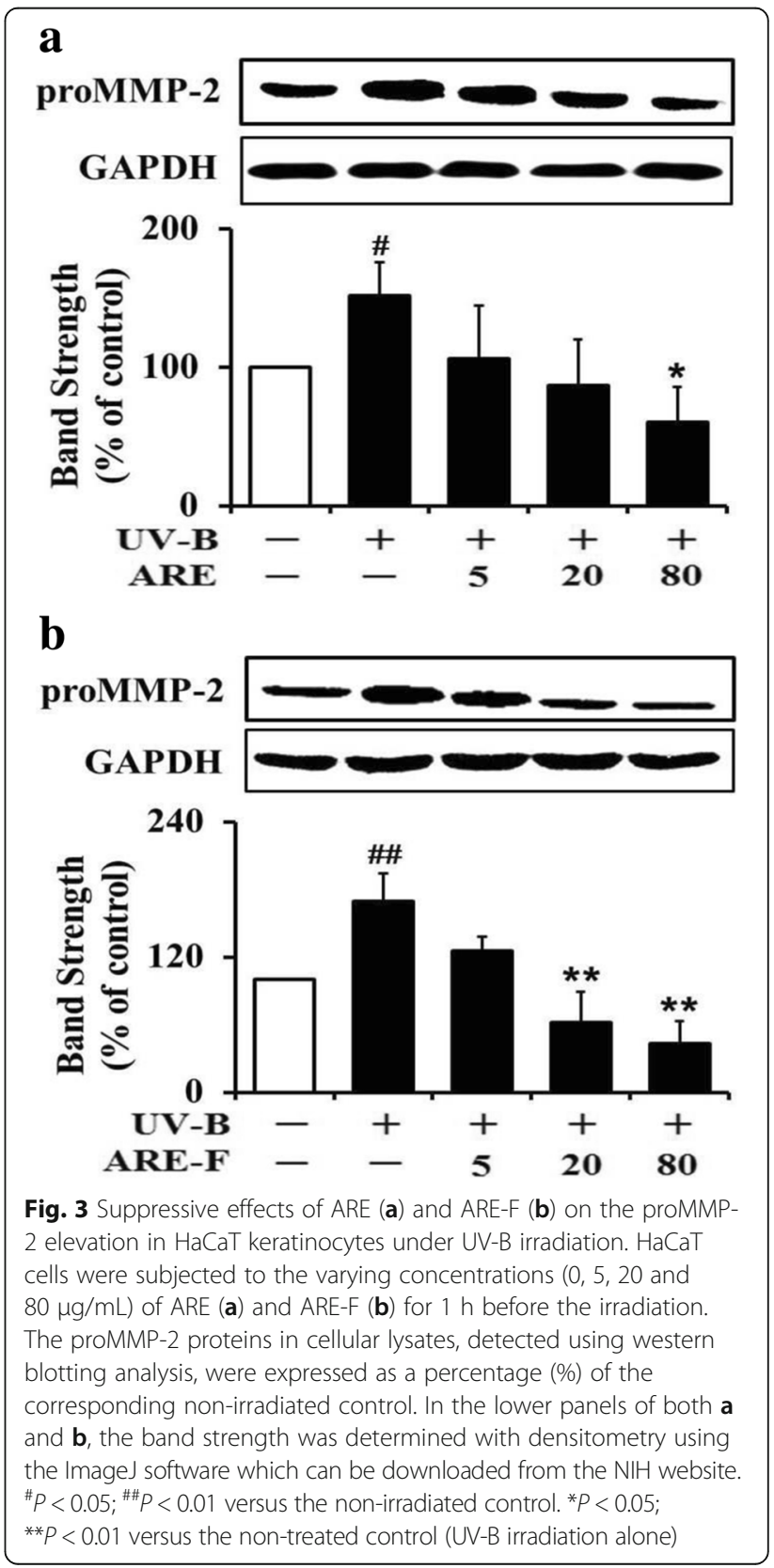


the concentrations of 5,20 and $80 \mu \mathrm{g} / \mathrm{mL}$ attenuated the UV-B-induced proMMP-2 protein to $69.5,57.6$ and $39.0 \%$ of that of the UV-B irradiation only (Fig. 3a). In an analogous experiment, ARE-F at the concentrations of 5, 20 and $80 \mu \mathrm{g} / \mathrm{mL}$ could attenuate the UV-B-induced proMMP-2 protein levels to $74.1,37.0$ and $26.0 \%$, respectively, of that of the UV-B irradiation only (Fig. 3b). The $\mathrm{IC}_{50}$ values of $\mathrm{ARE}$ and ARE-F were determined to be 48 . 3 and $27.9 \mu \mathrm{g} / \mathrm{mL}$. Taken together, the proMMP-2downregulating activity of ARE is also enhanced by probiotic fermentation.

\section{Total glutathione (GSH)}

GSH plays a protective property against oxidative stress in various cell types, including skin cells and has its protective property against oxidative stress via directly or indirectly scavenging ROS. In the previous work, total $\mathrm{GSH}$, including oxidized and reduced GSH, was shown to decline in UV-B-irradiated keratinocytes [29]. Likewise, total GSH levels were significantly decreased in $\mathrm{HaCaT}$ keratinocytes under UV-B irradiation, compared to the non-irradiated control value (Fig. 4). ARE at the concentrations of 5, 20 and $80 \mu \mathrm{g} / \mathrm{mL}$ enhanced the UVB-reduced total GSH levels to 1.1-, 1.6- and 1.7-fold of the non-treated value, respectively (Fig. 4a). Similarly, ARE-F at the concentrations of 5, 20 and $80 \mu \mathrm{g} / \mathrm{mL}$ was able to enhance the UV-B-reduced total GSH levels to 1 . 1-, 1.4- and 1.9-fold of the non-treated value, respectively (Fig. 4b). ARE and ARE-F at $80 \mu \mathrm{g} / \mathrm{mL}$ could restore the UV-B-reduced total GSH levels to 80.0 and $111.2 \%$, respectively, of the non-irradiated value (Fig. 4). This finding implies that the GSH-restoring activity of ARE on the UV-B-reduced total GSH levels is enhanced by probiotic fermentation.

\section{Total superoxide dismutase (SOD)}

SOD, deeply involved in the defensive mechanisms against oxidative stress, was previously identified to decline in UV-B-irradiated keratinocytes [30]. In this work, UV-B irradiation markedly diminished the total SOD activity, compared to the non-irradiated value (Fig. 5). As shown in Fig. 5a, ARE at the concentrations of 5, 20 and $80 \mu \mathrm{g} / \mathrm{mL}$ enhanced the UV-B-reduced SOD activity to 1.3-, 1.4 and 1.4-fold over that of the UV-B irradiation only. ARE-F at the concentrations of 5, 20 and $80 \mu \mathrm{g} /$ $\mathrm{mL}$ was able to increase the UV-B-reduced total SOD activity to 1.1-, 1.6- and 1.8-fold, respectively, over that of the UV-B irradiation only (Fig. 5b). ARE and ARE-F at the concentration of $80 \mu \mathrm{g} / \mathrm{mL}$ could restore the UV-Breduced total SOD activity levels to 70.4 and $110.2 \%$, respectively, over that of the non-irradiation only (Fig. 5). Taken together, the SOD-restoring activity of ARE is upregulated by probiotic fermentation.

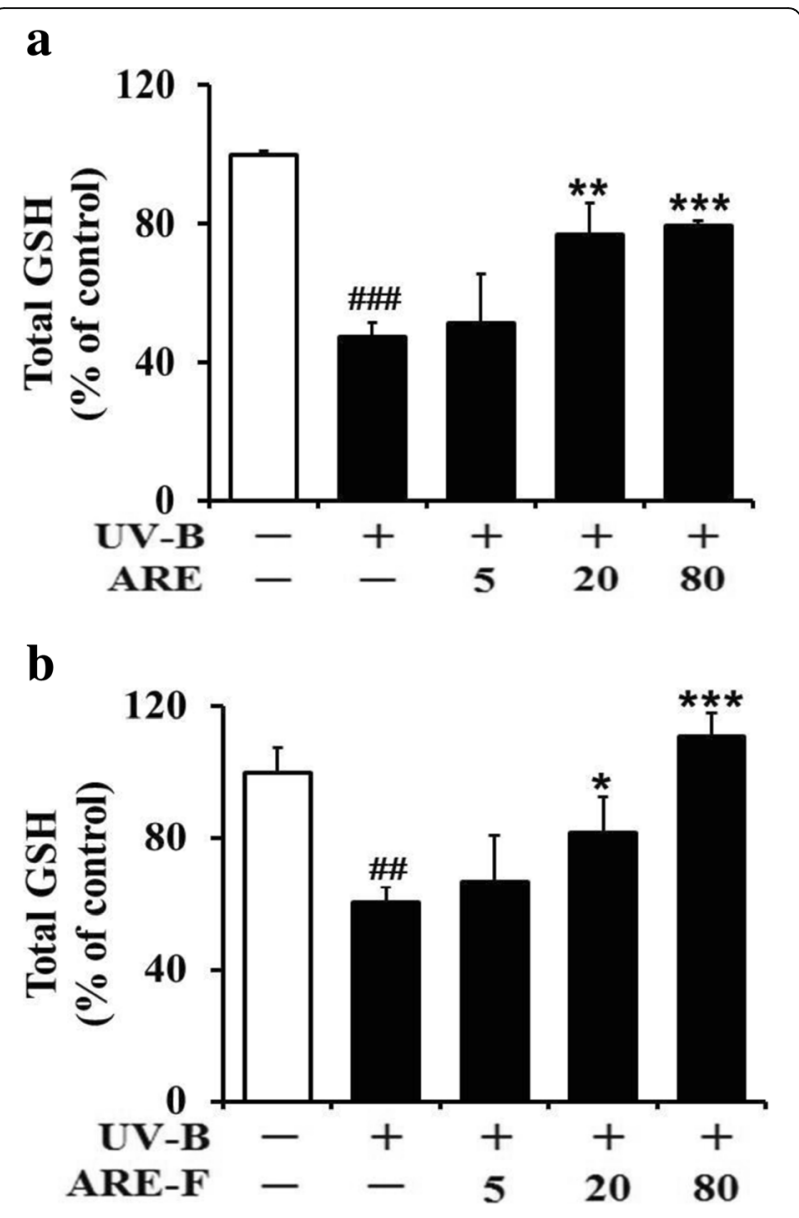

Fig. 4 Enhancing effects of $A R E$ (a) and ARE-F (b) on the total GSH attenuation in $\mathrm{HaCaT}$ keratinocytes under UV-B irradiation. HaCaT cells were subjected to the varying concentrations $(0,5,20$ and $80 \mu \mathrm{g} / \mathrm{mL}$ ) of ARE (a) and ARE-F (b) for $1 \mathrm{~h}$ before the irradiation. The total GSH content in the cellular lysates, quantitated with an enzymatic recycling assay using GR, was expressed as a percentage (\%) of the corresponding non-irradiated control. ${ }^{\# \#} P<0.01$; ${ }^{\# \# \# P} P<0.001$ versus the non-irradiated control. ${ }^{*} P<0.05$; ${ }^{*} P<0.01$; ${ }^{* *} P<0.001$ versus the non-treated control (UV-B irradiation alone)

In vitro antiradical activity

In order to compare the antiradical activities of ARE and ARE-F, the ABTS radical scavenging assay was conducted. AA, used as a positive control, was found to display an $\mathrm{SC}_{50}$ of $49.0 \mu \mathrm{g} / \mathrm{mL}$ (Fig. 6). Both ARE and ARE-F exhibited relatively weak ABTS radical scavenging activities, compared to AA and they didn't display a significant difference in ABTS radical scavenging activities (Fig. 6). This result suggests that the potentiation of the skin anti-photoaging properties of ARE by probiotic fermentation might not be irrespective of a change in in vitro antiradical activity.

\section{Discussion}

Through the recent years, the biological and pharmacological efficacies of $A$. rugosa have been continuously 


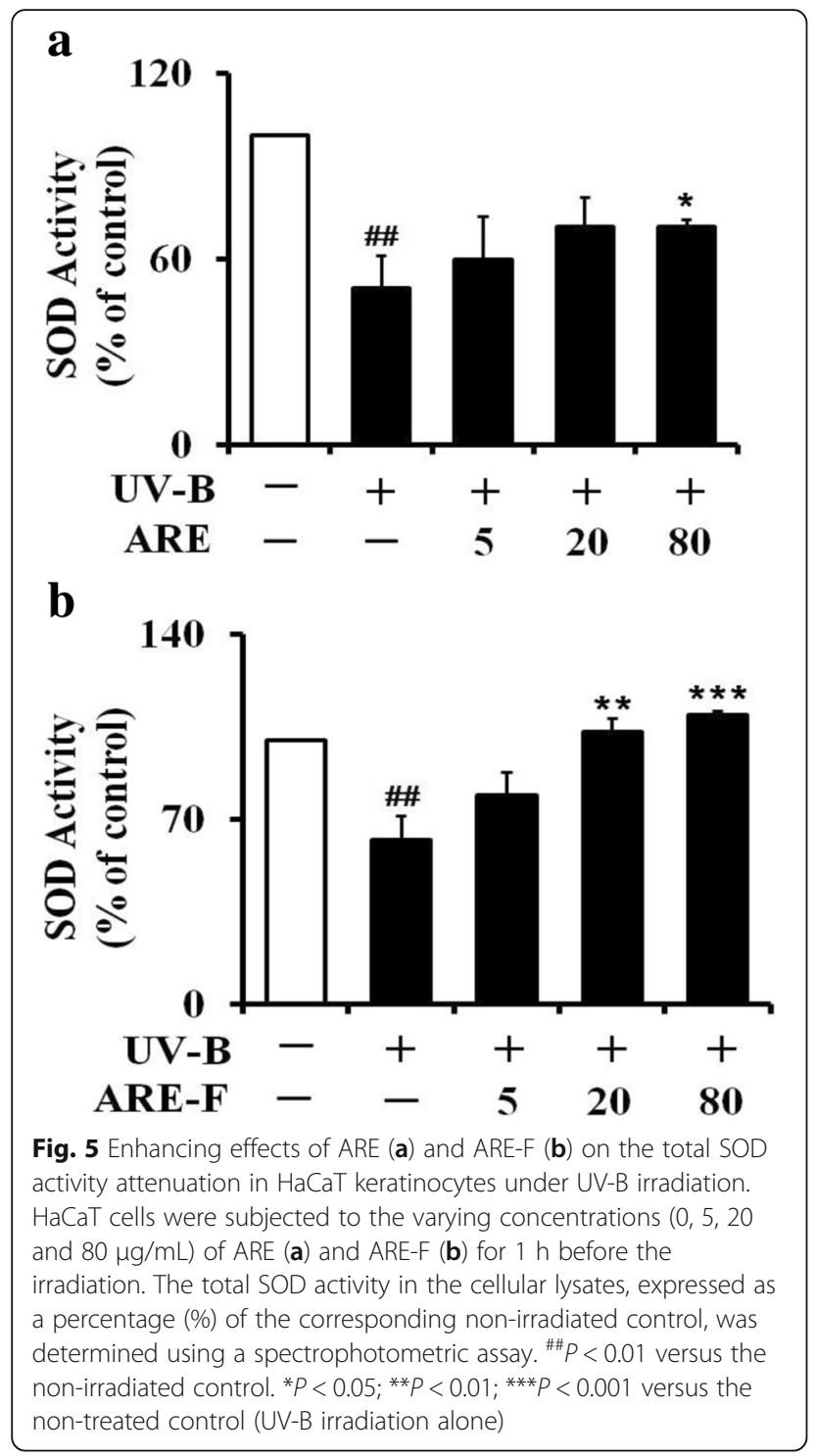

and extensively studied. An extract of $A$. rugosa leaves protects RAW264.7 cells from hydrogen peroxideinduced injury via the induction of protein kinase Gdependent heme oxygenase-1 [31]. Essential oils of $A$. rugosa leaves, whose major compounds are $p$-menthan-3one and estragole, have antimicrobial, antifilm and antitumor activities [32]. Demethyleugenol $\beta$-glucopyranoside, isolated from $A$. rugosa, possesses has an ameliorating activity on skin pigmentation by decreasing melanin synthesis via down-regulating microphthalmia-associated transcription factor and sex-determinating region Y-box 9 and subsequently resulting in a decrease in melanogenic enzymes, such as tyrosinase, tyrosinase-related protein 1 and dopachrome tautomerase [33]. An ethanol extract of A. rugosa leaves has an antimelanogenic activity through the suppression of tyrosinase, which is enhanced by the fermentation with L. rhamnosus and L. paracasei [34].

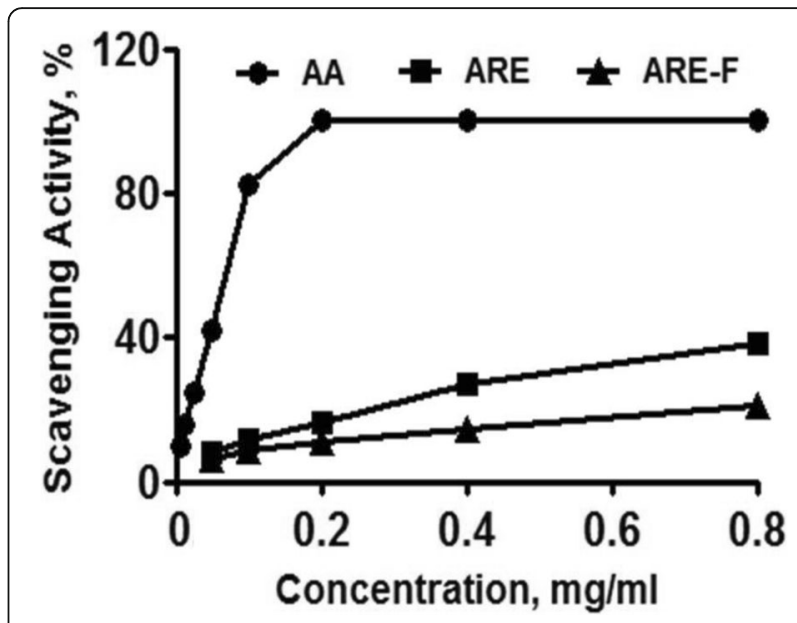

Fig. 6 The ABTS radical scavenging activities of $A R E$ and $A R E-F$. AA was used as a positive control. Each value shows the mean \pm SD of the three independent experiments repeated in triplicate

Addition of yeast extract, as an elicitor, to the A. rugosa culture enhances the accumulation of rosmarinic acid, a main phenylpropanoid of $A$. rugosa, through the upregulation of phenylpropanoid biosynthetic pathway genes, such as hydroxyl phenylpyruvate reductase and rosmarinic acid synthase genes [35]. A hot water extract of A. rugosa leaves have skin anti-photoaging property against UV-Binduced photooxidative stress in human keratinocytes via up-regulating GSH and SOD [22]. These findings further support the valuable application potential of $A$. rugosa in the manufacture of functional cosmetics. Enhancement of the desirable efficacies of $A$. rugosa would make its application more convenient and more economical.

Since useful phytochemicals, as nature's chemicals, are believed to be more safe than synthetic chemicals, they increasingly attract great interest in the healthcare, food, flavor and cosmetics industries. Fermentation of phytochemicals is a crucial processing method and is attracting a lot of attention since it may have the advantage of having novel and augmented biological functions. Desirable cosmetic ingredients need to contain attractive properties, including antioxidant, anti-inflammatory, skin whitening, anti-aging, moisturizing, bio-anti-wrinkle activities and so on [36]. During fermentation processing, microbes, including lactic acid bacteria, can improve the cellular functions of plant materials through their enzymatic activities, which promotes the production of a variety of metabolites and/or the release of functional components that are cryptic in non-fermented materials [37]. Bioconversion using whole cells is usually more stable, inexpensive and convenient than that using a purified enzyme [38]. Some biosurfactant extracts from Chinese medical herb fermentation exhibit favorable antioxidative, emulsifying and moisturizing properties in cosmetic formulations [39]. 
Fermentation with lactic acid bacteria is one of the most valuable tools to exploit the desirable functions of plant resources and to enrich them with bioactive compounds [40]. Fermentation with several lactic acid bacteria has been used to improve the antimicrobial, antioxidant and immunomodulatory activities of natural compounds of plant and microbial origins [41]. Phenolic compounds are well-known secondary metabolites of various plants that have been subjected to the lactic acid bacteria fermentation for studying the accompanying changes [42]. Bioconversion of baicalin and wogonoside to baicalein and wogonin, two main flavonoids exhibiting increased beneficial pharmacological properties in Scutellaria baicalensis, is significantly enhanced during fermentation using $\beta$-glucuronidase from $L$. brevis RO1 [43]. Myrtle berries homogenate, fermented with $L$. plantarum C2, was found to contain the increased antioxidant activity, probably based up on the increased concentrations of total phenols (mainly, gallic acid and ellagic acid), anthocyanins and flavonoids (mainly, myricetin and quercetin) [44]. Dried funori, a non-toxic, allnatural starch derived from seaweed (Gloiopeltis furcata and Gloiopeltis tenax), displays a significant enhancement in the superoxide anion radical-scavenging capacity after the fermentation with L. plantarum S-SU1 [45]. Fermentation of Psidium guajava fruit extract using L. plantarum NCIM 2912 enhances its antioxidant potential as well as total phenolics and short and medium chain fatty acid contents [46]. Fermenting a red ginseng extract with $L$. brevis enhances contents of ginsenoside metabolites, such as $\operatorname{Rg} 3, \operatorname{Rg} 5, \operatorname{Rk} 1$, compound $\mathrm{K}, \mathrm{Rh} 1, \mathrm{~F} 2 \mathrm{Rg} 2$, uronic acid, polyphenols and flavonoids, and subsequently offers increased anti-wrinkle and whitening efficacies and diminished toxicological potency [47]. L. plantarum- and Bifidobacterium bifidum-fermented aqueous extracts of Acanthopanax koreanum roots exhibit enhanced antioxidant and antisenescent activities against the exposure to UV-B irradiation and hydrogen peroxide, implying the improved anti-wrinkle effect on human skin [21]. The aloe fermentation supernatant fermented by $L$. plantarum possess enhanced antioxidant, antibacterial and anti-inflammatory activities [48]. In this work, we demonstrate that the skin anti-photoaging properties of a hot water extract of $A$. rugosa leaves are significantly augmented by the fermentation with L. rhamnosus HK-9, although the underlying mechanism currently remains uncertain. However, this result may elevate its application potential in cosmetics industries.

In this work, ARE-F tended to exhibit a diminished ABTS radical scavenging activity, compared to ARE, which might be contrary to its intracellular defensive properties in $\mathrm{HaCaT}$ keratinocytes. Although the cause of this discrepancy remains to be clarified, some findings on the reduction of antioxidant components and activities during fermentation were previously reported. The fermentation of strawberry must with Saccharomyces cerevisiae was found to diminish the ABTS and 2,2-diphenyl-1-picrylhydrazyl (DPPH) radical scavenging activities [49]. The liquid state fermentations of in vitro sprout and shoot cultures of java tea with $L$. acidophilus and L. plantarum cause a significant reduction in the levels of rosmarinic acid and total phenolic compounds and a loss of antioxidant activities, such as DPPH and ABTS scavenging activities and SOD-like activity $[50,51]$. In these experiments, the degree of reduction in some antioxidant components and activities was found to depend on the fermentation parameters, such as probiotic strains, fermentation temperature and fermentation period. Further approaches in future would help understand the discrepancy obtained in this work.

\section{Conclusions}

In conclusion, the present work demonstrates that the fermentation of $A$. rugosa leaf extract with a probiotic Lactobacillus strain improves its skin anti-photoaging properties through further augmenting UV-B-reduced total GSH and SOD activity levels and increasingly attenuating UV-B-induced ROS and MMP-2 and -9 levels in some sequential order. These findings imply the potential augmentation of the skin anti-photoaging properties of $A$. rugosa by probiotic fermentation, which can expand its usefulness in various applications, including cosmetic manufacture.

\section{Abbreviations \\ AA: ascorbic acid; ABTS: 2,2-azino-bis(3-ethylbenzothiazoline-6-sulfonic acid); ARE: a non-fermented hot water extract of $A$. rugosa leaves; ARE-F: a fermented hot water extract of $A$. rugosa leaves; DCF, 2',7'-dichlorofluorescein: DCFH-DA, 2',7'-dichlorodihydrofluorescein diacetate; DMEM: Dulbecco's modified Eagle's medium; DNTB: 5,5'-dithiobis (2-nitrobenzoic acid); FBS: fetal bovine serum; GSH: glutathione; GAPDH: glyceraldehyde 3-phosphate dehydrogenase; GR: Glutathione reductase; IC 50 : 50\% inhibitory concentration; MMP: Matrix metalloproteinase; PBS: Phosphate-buffered saline; proMMP: promatrix metalloproteinase; ROS: Reactive oxygen species; $\mathrm{SC}_{50}$ : 50\% scavenging concentration; SOD: Superoxide dismutase; UV-B: Ultraviolet-B}

\section{Acknowledgements}

The authors are very grateful to Ms. Su Hee Lee for her technical assistance.

\section{Funding}

This study was supported by a grant of the Korean Health Technology R\&D Project (Grant No.HN14C0081), the Ministry of Health \& Welfare, Republic of Korea.

\section{Availability of data and materials}

The data and materials of this work are available to other researchers upon request.

\section{Authors' contributions}

DS, YHH, HWL, DDK and CJL participated in the design of this work. DS, YHH, $\mathrm{KJ}$ and $\mathrm{YL}$ performed the experiments. $\mathrm{KJ}$ and $\mathrm{YL}$ analyzed the data. $\mathrm{HWL}$, DDK and CJL supervised this work and wrote the manuscript. All authors read the final manuscript and approved it for submission. 


\section{Competing interests}

The authors declare that they have no competing interests.

\section{Publisher's Note}

Springer Nature remains neutral with regard to jurisdictional claims in published maps and institutional affiliations.

\section{Author details}

'R \& D Center, Cosmocos Corporation, Incheon 21698, Republic of Korea. ${ }^{2}$ College of Pharmacy and Research Institute of Pharmaceutical Sciences, Seoul National University, Seoul 08826, Republic of Korea. ${ }^{3} R$ \& D Center, Shebah Biotech Inc., G-Tech Village, Chuncheon 24398, Republic of Korea. ${ }^{4}$ Department of Biochemistry, College of Natural Sciences, Kangwon National University, Chuncheon 24341, Republic of Korea.

\section{Received: 5 October 2017 Accepted: 8 April 2018}

\section{Published online: 26 June 2018}

\section{References}

1. Jenkins G. Molecular mechanisms of skin ageing. Mech Ageing Dev. 2002;123(7):801-10

2. Mohamed MA, Jung M, Lee SM, Lee TH, Kim J. Protective effect of Disporum sessile D.Don extract against UVB-induced photoaging via suppressing MMP-1 expression and collagen degradation in human skin cells. J Photochem Photobiol B. 2014:133:73-9.

3. Hseu YC, Chou CW, Senthil Kumar KJ, Fu KT, Wang HM, Hsu LS, et al. Ellagic acid protects human keratinocyte ( $\mathrm{HaCaT}$ ) cells against UVA-induced oxidative stress and apoptosis through the upregulation of the HO-1 and Nrf-2 antioxidant genes. Food Chem Toxicol. 2012;50(5):1245-55.

4. Piao MJ, Kim KC, Zheng J, Yao CW, Cha JW, Boo SJ, et al. The ethyl acetate fraction of Sargassum muticum attenuates ultraviolet B radiation-induced apoptotic cell death via regulation of MAPK- and caspase-dependent signaling pathways in human $\mathrm{HaCaT}$ keratinocytes. Pharm Biol. 2014;52(9):1110-8

5. F'guyer S, Afaq F, Mukhtar H. Photochemoprevention of skin cancer by botanical agents. Photodermatol Photoimmunol Photomed. 2003:19(2):56-72.

6. Cadet J, Sage E, Douki T. Ultraviolet radiation-mediated damage to cellular DNA. Mutat Res. 2005;571(1-2):3-17.

7. Aoki-Yoshida A, Aoki R, Takayama Y. Protective effect of pyruvate against UVB-induced damage in $\mathrm{HaCaT}$ human keratinocytes. J Biosci Bioeng. 2013;115(4):442-8.

8. Fisher GJ, Wang ZQ, Datta SC, Varani J, Kang S, Voorhees JJ. Pathophysiology of premature skin aging induced by ultraviolet light. N Engl J Med. 1997; 337(20):1419-28

9. Varani J, Hattori Y, Chi Y, Schmidt T, Perone P, Zeigler ME, et al. Collagenolytic and gelatinolytic matrix metalloproteinases and their inhibitors in basal cell carcinoma of skin: comparison with normal skin Br J Cancer. 2000;82(3):657-65.

10. Inomata S, Matsunaga Y, Amano S, Takada K, Kobayashi K, Tsunenaga $M$, et al. Possible involvement of gelatinases in basement membrane damage and wrinkle formation in chronically ultraviolet B-exposed hairless mouse. J Invest Dermatol. 2003;120(1):128-34.

11. Reel B, Oktay G, Ozkal S, Islekel H, Ozer E, Ozsarlak-Sozer G, et al. MMP-2 and MMP-9 alteration in response to collaring in rabbits: the effects of endothelin receptor antagonism. J Cardiovasc Pharmacol Ther. 2009;14(4):292-301.

12. Piao MJ, Susara Ruwan Kumara MH, Kim KC, Kang KA, Kang HK, Lee NH, et al. Diphlorethohydroxycarmalol suppresses ultraviolet B-induced matrix metalloproteinases via inhibition of JNK and ERK signaling in human keratinocytes. Biomol Ther (Seoul). 2015;23(6):557-63.

13. Kim YB, Kim JK, Uddin MR, Xu H, Park WT, Tuan PA, et al. Metabolomics analysis and biosynthesis of rosmarinic acid in Agastache rugosa Kuntze treated with methyl jasmonate. PLoS One. 2013;8(5):e64199.

14. Li HQ, Liu QZ, Liu ZL, Du SS, Deng ZW. Chemical composition and nematicidal activity of essential oil of Agastache rugosa against Meloidogyne incognita. Molecules. 2013;18(4):4170-80.

15. Min BS, Hattori M, Lee HK, Kim YH. Inhibitory constituents against HIV-1 protease from Agastache rugosa. Arch Pharm Res. 1999;22(1):75-7.

16. Lee C, Kim H, Kho Y. Agastinol and agastenol, novel lignans from Agastache rugosa and their evaluation in an apoptosis inhibition assay. J Nat Prod. 2002;65(3):414-6.
17. Hong JJ, Choi JH, Oh SR, Lee HK, Park JH, Lee KY, et al. Inhibition of cytokineinduced vascular cell adhesion molecule-1 expression; possible mechanism for anti-atherogenic effect of Agastache rugosa. FEBS Lett. 2001;495(3):142-7.

18. Gao LP, Wei HL, Zhao HS, Xiao SY, Zheng RL. Antiapoptotic and antioxidant effects of rosmarinic acid in astrocytes. Pharmazie. 2005;60(1):62-5.

19. Swarup V, Ghosh J, Ghosh S, Saxena A, Basu A. Antiviral and anti-inflammatory effects of rosmarinic acid in an experimental murine model of Japanese encephalitis. Antimicrob Agents Chemother. 2007;51(9):3367-70.

20. Tuan PA, Park WT, Xu H, Park NI, Park SU. Accumulation of tilianin and rosmarinic acid and expression of phenylpropanoid biosynthetic genes in Agastache rugosa. J Agric Food Chem. 2012;60(23):5945-51.

21. Park MJ, Bae YS. Fermented Acanthopanax koreanum root extract reduces UVB- and $\mathrm{H}_{2} \mathrm{O}$-induced senescence in human skin fibroblast cells. J Microbiol Biotechnol. 2016;26(7):1224-33.

22. Oh Y, Lim HW, Huang YH, Kwon HS, Jin CD, Kim K, et al. Attenuating properties of Agastache rugosa leaf extract against ultraviolet-B-induced photoaging via up-regulating glutathione and superoxide dismutase in a human keratinocyte cell line. J Photochem Photobiol B. 2016;163:170-6.

23. Bradford MM. A rapid and sensitive method for the quantitation of microgram quantities of protein utilizing the principle of protein-dye binding. Anal Biochem. 1976;72(1-2):248-54.

24. Royall JA, Ischiropoulos $\mathrm{H}$. Evaluation of $2^{\prime}, 7^{\prime}$-dichlorofluorescin and dihydrorhodamine 123 as fluorescent probes for intracellular $\mathrm{H}_{2} \mathrm{O}_{2}$ in cultured endothelial cells. Arch Biochem Biophys. 1993;302(2):348-55.

25. Nakagawa K, Saijo N, Tsuchida S, Sakai M, Tsunokawa Y, Yokota J, et al. Glutathione-S-transferase $\pi$ as a determinant of drug resistance in transfectant cell lines. J Biol Chem. 1990;265(8):4296-301.

26. Lee YY, Kim HG, Jung HI, Shin YH, Hong SM, Park EH, et al. Activities of antioxidant and redox enzymes in human normal hepatic and hepatoma cell lines. Mol Cells. 2002;14(2):305-11.

27. Re R, Pellegrini N, Proteggente A, Pannala A, Yang M, Rice-Evans C. Antioxidant activity applying an improved ABTS radical cation decolorization assay. Free Radic Biol Med. 1999;26(9-10):1231-7.

28. Kim MS, Oh GH, Kim MJ, Hwang JK. Fucosterol inhibits matrix metalloproteinase expression and promotes type-1 procollagen production in UVB-induced HaCaT cells. Photochem Photobiol. 2013;89(4):911-8.

29. Zhu M, Bowden GT. Molecular mechanism(s) for UV-B irradiation-induced glutathione depletion in cultured human keratinocytes. Photochem Photobiol. 2004:80(2):191-6.

30. lizawa O, Kato T, Tagami H, Akamatsu H, Niwa Y. Long-term follow-up study of changes in lipid peroxide levels and the activity of superoxide dismutase, catalase and glutathione peroxidase in mouse skin after acute and chronic UV irradiation. Arch Dermatol Res. 1994;286(1):47-52.

31. Oh HM, Kang YJ, Lee YS, Park MK, Kim SH, Kim HJ, et al. Protein kinase G-dependent heme oxygenase-1 induction by Agastache rugosa leaf extract protects RAW264.7 cells from hydrogen peroxide-induced injury. J Ethnopharmacol. 2006;103(2):229-35.

32. Haiyan G, Lijuan H, Shaoyu L, Chen Z, Ashraf MA. Antimicrobial, antibiofilm and antitumor activities of essential oil of Agastache rugosa from Xinjiang, China. Saudi J Biol Sci. 2016:23(4):524-30.

33. Lee TH, Park S, Yoo G, Jang C, Kim MH, Kim SH, et al. Demethyleugenol $\beta$-glucopyranoside isolated from Agastache rugosa decreases melanin synthesis via down-regulation of MITF and SOX9. J Agric Food Chem. 2016;64(41):7733-42.

34. Kim NY, Kwon HS, Lee HY. Effect of inhibition on tyrosinase and melanogenesis of Agastache rugosa Kuntze by lactic acid bacteria fermentation. J Cosmet Dermatol. 2017;16(3):407-15.

35. Park MJ, Bae YS. Fermented Acanthopanax koreanum root extract reduces UVB- and $\mathrm{H}_{2} \mathrm{O}_{2}$-induced senescence in human skin fibroblast cells. J Microbiol Biotechnol. 2016;26(7):1224-33.

36. Katina $\mathrm{K}$, Laitila A, Juvonen $\mathrm{R}$, Liukkonen $\mathrm{KH}$, Kariluoto $\mathrm{S}$, Piironen $\mathrm{V}$, et al. Bran fermentation as a means to enhance technological properties and bioactivity of rye. Food Microbiol. 2007:24(2):175-86.

37. Gobbetti M, Cagno RD, De Angelis M. Functional microorganisms for functional food quality. Crit Rev Food Sci Nutr. 2010;50(8):716-27.

38. Faber K. Biotransformation in organic chemistry: a textbook. 5th ed. Germany: Springer; 2004. p. 25-6.

39. Chen C, Lin T, Shieh Y. Emulsification and antioxidation of biosurfactant extracts from Chinese medicinal herbs fermentation in vitro. J Biosci Bioeng. 2015;120(4):387-95. 
40. Pellati F, Benvenuti S, Magro L, Melegari M, Soragni F. Analysis of phenolic compounds and radical scavenging activity of Echinacea spp. J Pharm Biomed Anal. 2004;35(2):289-301.

41. Rizzello CG, Coda R, Macías DS, Pinto D, Marzani B, Filannino P, et al. Lactic acid fermentation as a tool to enhance the functional features of Echinacea spp. Microb Cell Factories. 2013;12(1):44.

42. Liu S, Han Y, Zhou Z. Lactic acid bacteria in traditional fermented Chinese foods. Food Res Int. 2011;44(3):643-51.

43. Xu C, Ji GE. Bioconversion of flavones during fermentation in milk containing Scutellaria baicalensis extract by Lactobacillus brevis. J Microbiol Biotechnol. 2013;23(10):1422-7.

44. Curiel JA, Pinto D, Marzani B, Filannino P, Farris GA, Gobbetti M, et al. Lactic acid fermentation as a tool to enhance the antioxidant properties of Myrtus communis berries. Microb Cell Factories. 2015;14(1):67.

45. Kuda T, Nemoto M, Kawahara M, Oshio S, Takahashi H, Kimura B. Induction of the superoxide anion radical scavenging capacity of dried 'funori' Gloiopeltis furcata by Lactobacillus plantarum S-SU1 fermentation. Food Funct. 2015;6(8):2535-41.

46. Bhat R, Suryanarayana LC, Chandrashekara KA, Krishnan PA, Kush A, Ravikumar P. Lactobacillus plantarum mediated fermentation of Psidium guajava L. fruit extract. J Biosci Bioeng. 2015;119(4):430-2.

47. Lee HS, Kim MR, Park Y, Park HJ, Chang UJ, Kim SY, et al. Fermenting red ginseng enhances its safety and efficacy as a novel skin care anti-aging ingredient: in vitro and animal study. J Med Food. 2012;15(11):1015-23.

48. Jiang M, Deng K, Jiang C, Fu M, Guo C, Wang X, et al. Evaluation of the antioxidative, antibacterial, and anti-inflammatory effects of the aloe fermentation supernatant containing Lactobacillus plantarum HM218749.1. Mediat Inflamm. 2016;2016:2945650

49. Lee PJ, Chen S. Effect of adding ball-milled achenes to must on bioactive compounds and antioxidant activities in fruit wine. J Food Sci Technol. 2016;53(3):1551-60.

50. Hunaefi D, Akumo DN, Riedel H, Smetanska I. The effect of Lactobacillus plantarum ATCC 8014 and Lactobacillus acidophilus NCFM fermentation on antioxidant properties of selected in vitro sprout culture of Orthosiphon aristatus (java tea) as a model study. Antioxidants (Basel). 2012;1(1):4-32.

51. Hunaefi D, Riedel H, Akumo DN, Gruda N, Smetanska I. Effect of lactic acid fermentation on rosmarinic acid and antioxidant properties of in vitro shoot culture of Orthosiphon aristatus as a model study. Food Biotechnol. 2013:27(2):152-77

\section{Ready to submit your research? Choose BMC and benefit from:}

- fast, convenient online submission

- thorough peer review by experienced researchers in your field

- rapid publication on acceptance

- support for research data, including large and complex data types

- gold Open Access which fosters wider collaboration and increased citations - maximum visibility for your research: over $100 \mathrm{M}$ website views per year 